Phoey Lee Teh, Jin Quan Low, Yain-Whar Si 2020, Geographical distance and news diffusion associating with the sentiment of tweets: Case Study on London Bridge Attach 2017. 6 pages. Pending DOI: Will update soon.

\title{
Geographical distance and news diffusion associating with the sentiment of tweets: Case Study on London Bridge Attack 2017
}

\author{
Phoey Lee Teh \\ Department of Computing and \\ Information Systems, \\ School of Science and Technology, \\ Sunway University Malaysia \\ phoeyleet@sunway.edu.my
}

\author{
Jin Quan Low \\ Department of Computing and \\ Information Systems, \\ School of Science and Technology, \\ Sunway University, \\ 16091373@imail.sunway.edu.my
}

\author{
Yain-Whar Si \\ Department of Computer and \\ Information Science \\ Faculty of Science and Technology, \\ University of Macau, \\ fstasp@umac.mo
}

\begin{abstract}
This article aims to explore how could distance affect news diffusion and polarity of the sentiment. Understanding the estimation potential point of origin of news diffusion can allow time to control or monitor the potential of fake news to continue to disperse. In this case, we collect a total of 10,427 English tweets posted 1 hour after the real incident of London bridge attack. Taking into consideration that the ground zero as the place of attack, for an accumulating buffer of radius expanding with $400 \mathrm{~km}$ from ground zero geographically, we organise tweets into ten clusters sets and analyse it. News diffusion level associating with the polarity of the sentiment of news discussed, and the type of terms that frequently used within the radius are also analysed.
\end{abstract}

Keywords- tweets; sentiment analysis; news diffusion; geographical distance.

\section{INTRODUCTION}

On June 201710 pm, a terrorist vehicle-ramming and stabbing took place near London Bridge, England. Three attackers ran to nearby Borough Market area and stabbed people in and around restaurants and pubs. They were shot dead by police officers. There were 8 people killed, and 48 injured. BBC News reports this news and has caused a worldwide sensation. Public around the world react by posting their opinions on Twitter and Facebook. As assumed in traditional news diffusion studies [1], the news is frequently treated as immutable information. It can influence citizens' opinions and are define as valence evaluations of a targeted object in public opinion literature [2].

Public opinion defined as communication processes through which publics are constituted and within which opinion on public affairs are formed [3]. The society's reaction towards a piece of news that they assume as wellstudied. Mainly, it is about how a News is born, developed and resided in the public sphere [4][5][6] [7]. In this sense, the opinion refers to the interpretation of a news event, as does the term news is framed [8][9]. The creation of public opinion happened when debate or discussion occurred and declined with silence later in public.

Public opinion's perceptions play an essential role in the "spiral of silence" [10]. From the theory of "spiral of silence", it is assumed that the willingness of people to speak out publicly on morally loaded issues depends on their perceptions of majority opinions in society. With the appearance of public support towards their view, individuals will increase their willingness to speak out, while realising themselves as the minority will cause them to fall silent [10].

This study intends to explore if the perceptions of majority opinions in society are consistent within their sentiment, or contradicting to each other. And how it affects the changes (if any) within an evenly distributed tweets geographical different.

\section{RELATED WORKS}

A study about the level of government activity involved in governmental renewable energy policy and how it has correlated with changing levels of public opinion support toward environmental protection was performed [7]. It has contributed additional evidence suggests there is an increase of role for participants in the renewable energy policy department and non-government stakeholders from the government themselves. It has proven that public opinion brought impact to specific fields, but what about the aspect of news and how public opinion related to it? For more than a decade, questions regarding the traditional news media's influence on public opinion have been a matter of heated debate. With the rapid growth and transformations of the media environment, which signify contemporary democracies, the relevance and reliability of classic media effect theories are now frequently questioned [11][12]. The basic idea of traditional media and mass communication effects theories is that public opinion is responsive to the dominant messages provided by the news media. It is not to say that media coverage affects all citizens in equally; extensive research has identified a range of contingent factors. These 
theories are all based on the premise that media attention to various political issues or frames matters of public opinion formation [13][14].

The probability of differential consequences on public opinion estimates is less transparent depending on either the news if watch from Online TV or online Internet. Kiousis's study has found that news credibility was correlated across channels, that the credibility level of newspapers is only slightly higher than the Internet as a news medium [15]. Differences in the content were detected when Web-based and print edition of six Colorado newspapers are compared by Singer [16]. Thus, the probability of people who read online versions of major news publications will have a different impression in public sentiment, and it based on the variations in perceived credibility or slant of content relative to Internetonly news sites [17].

The ease of use in social media applications has changed how people communicate with each other. Due to the amount of news information produced from social network sites, it becomes one of the most preferred information sources. Its role as an information source stands out significantly during crises such as natural disaster and terrorism [18][19][20][21]. Important events and breaking news spread instantly through social media than follow with the conventional news media. The credibility of the information has come across to be questionable compared to conventional news media and social media. Because online social media users could provide a report and re-share [22] information, especially adding with their new opinions with individual biases, perceptions and purposes of spreading the news; hence became less trustworthy.

Measuring the credibility of information can be extremely hard to carry out. Credible information has a requirement that it is trusted, reliable, neutral and fair [23]. Credibility assessment and model is used in capitalises online social networks [24]. Given a particular topic issue, a system with this model will retrieve user sentiments and responses on the issue from Twitter as the primary information of sources to evaluate its credibility. Then we select certain representative user opinion that could be pointed out as a means to explain the credibility value. Sentiment types will not only be analysed to the category of positive, neutral and negative, for further, but it will also be cluster whether it is supporting or opposing opinions towards the topic discussed. If people are showing evidence that they agree with the content, only the information is considered credible.

In this age of news media, it is particularity worth to study social responses. Search engines such as Google and social networks such as Facebook and Twitter, rely on complex algorithms to show topics to the user. It shows what you want to see, produce alternate information environments whose implications for foreign policy opinion are not yet fully appreciated [25] [26]. However, public opinion on the online social network is challenging to manage and study suggested that the results of the analysis of the geographic characteristics give some new ideas and strategy to address the online public opinion [27]. The similarity of national and state-level patterns suggest that similar issues were influencing trends in the national and state level in the same way [34]. The propagation of public opinion has its characteristics. Social and monetary conditions generally shift in various territories. Therefore, different geographical area, public opinion might be different from a different cultural and economic situation [28]. Surowiecki claimed that we could derive the truth, which could not be confirmed by anyone, by gathering and consolidating opinions of different people, which possess different positions and in a different location [29]. In other words, we perform the majority decision to assess the credibility of tweets.

The following are the research question:

Q1: Association between the level of credibility of news vs geographical location?

Q2. Association between the polarity of the sentiment vs geographical location?

Q3: How people from different locations (by distance) "react" to the news differently?

Q4: Can sentiment (positive, neutral, negative) affect the level of credibility of public opinion?

\section{METHOD}

\section{A. Data Collection}

A total of 10427 English tweets was paid to trackmyhashtag.com to obtain the tweets of London Bridge Attack on the day after the attack of $10 \mathrm{pm}$ on the 3rd of June 2017. The data ended 24 hours of the 4th of June 2017, and the spread has arrived at an unbeliever level. TrackMyHashtag is a social media analytics tool which tracks all activities happening around a Twitter campaign. Texts From Twitter is read in real-time, recorded the historical tweets for all the time. The tweets purchased came with the exact posted along with attributes including date, time, name, username, etc.

\section{B. Sentiment Analysis}

Azura machine learning is an add-on towards excel to analyse the sentiment level of a context then categories them into positive, neutral and negative. For example, "With love, we are with you \#prayforlondon \#londonbridgeattack", is categorised as positive sentiment, with the words like 'love' or 'with you' appeared. "My heart bleeds at the news of \#LondonBridgeAttack, so sad, stay strong London." is an example of negative sentiment with words such as 'sad' and heart bleeds' shown up. Using Azura machine learning, we analysed all of the tweet contents and labelled each tweet into three categories, which is positive, neutral and negative. It helps us to perform analysis of credibility better in the future and observe sentiment level from different geographical locations.

\section{Distance Identification \& Grouping}

The data set provided with the tweet location of the users when the tweet is created. Using London as the center point, we determine the distance between London and the mentioned location in kilometres using Google Maps. There are only 5482 tweets were found with valid locations name attached to it. Therefore, we have new information which is the "Distance from London (in $\mathrm{km}$ )" connect with the category of the sentiment analysis. We used $400 \mathrm{~km}$ as our benchmark to evenly spread the distance from point zero. We have separated the data into 
ten groups based on "Distance from London (in $\mathrm{km}$ )" in Table I.

\section{Wmatrix}

WMatrix is a software tool for corpus analysis and comparison [30]. Using Wmatrix, we determine the highest frequency of words for each group. We also categorise the sentiment for those terms.

\section{E. Measuring the level fo credibility}

We assumed the topic discuss having a high level of similarity due to data are obtained with the prerequisite that it is related to London Bridge Attack and have the hashtag of "\#LondonBridgeAttack" in all tweets. To determine the credibility level from the users based on the context, we categorised each tweet into Support or Oppose the topic discussion. We use the model following four possible conditions to determine Support or Oppose below:

a) One of the tweets has contradicting word/phrase that is not found on the other.

b) One of the tweets has a word/phrase with the meaning opposite to the topic.

c) One of the tweets satisfies both conditions.

d) None of the claims satisfies above conditions.

If the tweet context satisfies exactly one condition (a) or (b) and not both are considered Oppose. If the tweet context satisfies either condition (c) or (d) are considered support.

TABLE I. COUNTRY AND CITIES WITHIN THE RADIUS FROM LONDON

\begin{tabular}{|c|c|c|}
\hline Group & $\begin{array}{l}\text { Distance from } \\
\text { London (in } \\
\text { km) }\end{array}$ & $\begin{array}{c}\text { Country and cities available within the } \\
\text { radius }\end{array}$ \\
\hline 1 & 0 & England \\
\hline 2 & 1 to 400 & Belgium, Burnley, Jersey \\
\hline 3 & 401 to 800 & $\begin{array}{l}\text { France, Netherlands, Ireland, Dublin, } \\
\text { Glasgow, Deutschland, Paris, Amsterdam }\end{array}$ \\
\hline 4 & 801 to 1200 & $\begin{array}{c}\text { Germany, Berlin, France, Switzerland, } \\
\text { Italy, Scotland, York }\end{array}$ \\
\hline 5 & 1201 to 1600 & $\begin{array}{c}\text { Denmark, Austria, Spain, Barcelona, } \\
\text { Scandinavia }\end{array}$ \\
\hline 6 & 1601 to 3200 & $\begin{array}{c}\text { Norge, Latvia, Portugal, Athens, Greece, } \\
\text { Norway, Brussel, Castilla, Turkey, } \\
\text { Sweden, Libya }\end{array}$ \\
\hline 7 & 3201 to 4800 & Syria, Georgia, Charlottetown \\
\hline 8 & 4801 to 6400 & $\begin{array}{c}\text { Canada, Virginia, USA, Pakistan, Israel, } \\
\text { Russia, Saudi Arabi }\end{array}$ \\
\hline 9 & 6401 to 8000 & $\begin{array}{c}\text { USA, Qatar, India, Georgia, Nigeria, } \\
\text { Dubai }\end{array}$ \\
\hline 10 & $\begin{array}{l}8001 \text { and } \\
\text { above }\end{array}$ & $\begin{array}{c}\text { Republic of Panama, Malaysia, USA, } \\
\text { Australia, Singapore, Japan, Brasil, South } \\
\text { Africa, New Zealand, Philippines, } \\
\text { Thailand, Kenya }\end{array}$ \\
\hline
\end{tabular}

To identify the contradicting words as in the condition (a) above is to use various pattern with lexical cues that can indicate a contradictive claim. For example, the claim of our topic which is "London Bridge got attack" as a pattern of "X Y" contradicts with a tweet of "London Bridge did not get attack" as a pattern of "X S Y", where S $\in\{$ "is not", "don't", "haven't", ... $\}$ and in this case, which $\mathrm{S}$ represents "did not". In condition (b), WordNet's antonym can be employed to check word with the opposite meaning. For example, "Trump win the 2016 election" has the opposite meaning with "Trump loses the 2016 election". From the example, "win" has the same meaning with "does not lose", which satisfies both conditions. Table II provides examples of cue phrases for confirmation and denial. The problem contradiction identification can also be approached using textual entailment. Several textual entailment algorithms have been developed, such as those based on symbolic meaning, logic-based approach, surface string, vector space model, rule extraction and combination of these approaches.

$$
\text { Credibility }=\text { Support }- \text { Oppose } / \text { Support }+ \text { Oppose }
$$

With the conditions mentioned above, Support and Oppose can now be determined to calculate the level of Credibility user have towards the topic for each group and overall of it.

TABLE II. EXAMPLE OF PHRASES FOR CONFIRMATION AND DENIAL

\begin{tabular}{|l|l|}
\hline \multicolumn{1}{|c|}{ Confirmation } & \multicolumn{1}{c|}{ Denial } \\
\hline $\begin{array}{l}\text { it's true } \\
\text { so true } \\
\text { believe that } \\
\text { truth that }\end{array}$ & $\begin{array}{l}\text { still rumours floating around } \\
\text { Who believes stuff like that? } \\
\text { it's not true that } \\
\text { be careful of what you read } \\
\text { misinformation about } \\
\text { this is fake }\end{array}$ \\
\hline
\end{tabular}

\section{RESULT}

\section{A. Sentiment Vs. Geographical Location}

TABLE III. GEOGRAPHICAL LOCATION AND ITS SENTIMENT

\begin{tabular}{|c|c|c|c|c|}
\hline Group & Frequency & \multicolumn{3}{|c|}{ Sentiment (\%) } \\
\hline \multirow{2}{*}{1} & \multirow{2}{*}{2163} & Positive & Neutral & Negative \\
\hline & & 39.25 & 20.62 & 40.13 \\
\hline 2 & 20 & 35 & 15 & 50 \\
\hline 3 & 114 & 43.86 & 21.93 & 34.21 \\
\hline 4 & 137 & 37.23 & 23.36 & 39.42 \\
\hline 5 & 17 & 17.65 & 41.18 & 41.18 \\
\hline 6 & 86 & 31.4 & 15.12 & 53.49 \\
\hline 7 & 3 & 33.33 & 33.33 & 33.33 \\
\hline 8 & 1014 & 38.07 & 29.49 & 32.45 \\
\hline 9 & 1336 & 43.11 & 23.65 & 33.23 \\
\hline 10 & 592 & 36.66 & 33.45 & 29.9 \\
\hline
\end{tabular}

B. Credibility vs geographical location

TABLE IV. GEOGRAPHICAL LOCATION AND ITS LEVEL OF CREDIBILITY 


\begin{tabular}{|c|c|c|}
\hline $\begin{array}{c}\text { Grou } \\
\text { p }\end{array}$ & $\begin{array}{c}\text { Level of } \\
\text { Credibility( } \\
\%)\end{array}$ & Top 20 Words Used \\
\hline \multirow[b]{2}{*}{1} & 99.31 & \multirow{2}{*}{$\begin{array}{l}\text { Wrong, proof, victims, muslim, treating, } \\
\text { consultant, nursing, colleague, abused, } \\
\text { police, leading, attack, victim, terrorist, } \\
\text { solidarity, racist, terrorists, abuse, strong, } \\
\text { stabbed, }\end{array}$} \\
\hline & $\begin{array}{c}\text { Support }=2148 \\
\text { Oppose }=15\end{array}$ & \\
\hline \multirow[b]{3}{*}{2} & 100 & \multirow{3}{*}{$\begin{array}{c}\text { Against, underlying, issue, attack, } \\
\text { terrorist, asylum_seekers, committed, } \\
\text { murder, safe, victims, laughing, stabbed, } \\
\text { slaughtered, suspected, radicalised, } \\
\text { arrested, counterterrorism, horrific, } \\
\text { police, extremists }\end{array}$} \\
\hline & Support $=20$ & \\
\hline & Oppose $=0$ & \\
\hline \multirow[b]{2}{*}{3} & 100 & \multirow{2}{*}{$\begin{array}{l}\text { Wrong, proof, victims, police, muslim, } \\
\text { terrorist, terrorists, abused, attacks, } \\
\text { prevent, threat, consultant, leading, } \\
\text { nursing, injured, killed, attack, victim, } \\
\text { extremist, terror }\end{array}$} \\
\hline & $\begin{array}{c}\text { Support }=114 \\
\text { Oppose }=0\end{array}$ & \\
\hline \multirow[b]{2}{*}{4} & 99.27 & \multirow{2}{*}{$\begin{array}{l}\text { Victims, wrong, proof, solidarity, } \\
\text { Muslim, support, consultant, leading, } \\
\text { nursing, colleague, abused, treating, } \\
\text { thanked, condolences, responsible, } \\
\text { terrorist, love, attack, secretary, offered }\end{array}$} \\
\hline & $\begin{array}{c}\text { Support }=136 \\
\text { Oppose }=1\end{array}$ & \\
\hline \multirow[b]{2}{*}{5} & 100 & \multirow{2}{*}{$\begin{array}{l}\text { Terror, attack, hooligans, victims, lost, } \\
\text { great, terrorism, sorry, kill, freedom, } \\
\text { horrific, shocked, saddened, victim, } \\
\text { wrong, proof, terrible, peace, suspect, } \\
\text { cheers }\end{array}$} \\
\hline & $\begin{array}{l}\text { Support }=17 \\
\text { Oppose }=0\end{array}$ & \\
\hline \multirow[b]{2}{*}{6} & 97.67 & \multirow{2}{*}{$\begin{array}{l}\text { Missing, attack, victims, wrong, } \\
\text { cowardly, worry, condolences, terrorists, } \\
\text { terrorist, attacks, terror, expressed, } \\
\text { solidarity, horrific, police, proof, } \\
\text { terrorism, consultant, Muslim, nursing }\end{array}$} \\
\hline & $\begin{array}{l}\text { Support }=84 \\
\text { Oppose }=2\end{array}$ & \\
\hline \multirow[b]{2}{*}{7} & 100 & \multirow{2}{*}{$\begin{array}{l}\text { Funding, caused, bombing, stabbed, } \\
\text { donors, supporting, recovery, lost, } \\
\text { cowardly, terrorist }\end{array}$} \\
\hline & Support=3 & \\
\hline \multirow[b]{2}{*}{8} & 97.73 & \multirow{2}{*}{$\begin{array}{c}\text { Attack, threat, prevent, spreading, victim, } \\
\text { wrong, proof, police, affairs, beautiful, } \\
\text { terrorist, victims, protest, against, } \\
\text { American, terrorism, worry, hit, attacks, } \\
\text { bullet }\end{array}$} \\
\hline & $\begin{array}{l}\text { Support }=991 \\
\text { Oppose }=23\end{array}$ & \\
\hline \multirow[b]{2}{*}{9} & 95.81 & \multirow{2}{*}{$\begin{array}{l}\text { Threat, prevent, right, terrorist, against, } \\
\text { terrorism, wrong, proof, worry, protest, } \\
\text { attack, citizens, police, unarmed, fight, } \\
\text { protect, armed, suicide, murder, } \\
\text { responsibility }\end{array}$} \\
\hline & $\begin{array}{c}\text { Support }=1280 \\
\text { Oppose }=56\end{array}$ & \\
\hline \multirow[b]{2}{*}{10} & 97.64 & \multirow{2}{*}{$\begin{array}{l}\text { Condemn, terror, victims, perpetrators, } \\
\text { cruel, funders, stopped, wrong, proof, } \\
\text { threat, prevent, police, against, attack, } \\
\text { Islam, stop, terrorist, killing, safe, peace }\end{array}$} \\
\hline & $\begin{array}{c}\text { Support }=578 \\
\text { Oppose }=14\end{array}$ & \\
\hline
\end{tabular}

Table III presents the geographical group, frequency and sentiment for each group. Table IV shows the support and oppose the condition for each group. From the algorithm used on methodology, all tweets only fall in either condition (b) represent Oppose or condition (d) represent Support. Overall of $10184(97.67 \%)$ tweets were identified support and $243(2.33 \%)$ tweets were Oppose.

Some examples that meet the condition of (b):

"Makes you wonder what else is staged? What else is HOAX? Wake up, people. \#cnnisisis \#FakenewsCNN \#hoax \#FakeNews \#LondonBridgeAttack"

"this video it shows the actual report that aired then shows the setup Classic \#FakenewsCNN \#LondonBridgeAttack." "Even my \#bulldog is disgusted with@CNN He hates \#fakenews Low-blow staging story fit \#falsenarrative \#LondonBridgeAttack"

It has shown that the authenticity of this news is being questioned and hashtag with the term "fake news" to voice out their opinion of justifying that this is not real. This tweet has contained Oppose meaning towards the topic being discussed. A few examples of a tweet that meet the condition of $(\mathrm{d})$ :

"We give thanks to the women and men of our emergency services who dealt with the \#LondonBridgeAttack with immense courage. We salute you."

"Will the British terror attacks affect the result? \#GE2017 \#GE17 \#LondonBridgeAttack"

"The world is a sad place. Too much violence going on. Thoughts are with the victims and families in London. \#LondonBridgeAttack"

This has shown the user discuss the topic directly without questioning the authenticity and it neither contains any contradicting words nor words that have meaning opposed to the case. The change of range for the level of credibility is extremely small, with Group 9 having $95.81 \%$ of credibility level as the lowest among all group, and Group 2,3,5,7 having $100 \%$ of credibility level. The mean for the level of credibility is $98.74 \%$ consider most of the user show support and discuss this topic directly and did not question the authenticity of it. Therefore, it is unable to identify any significant changes with the different locations.

There is a significant difference when it reaches Group 5 and 6 between positive and negative sentiment (Fig. 1), other than that, the percentage of positive and negative lies between 0.299 and 0.5349 . Due to Group 5 and 6 only have a frequency of 17 and 86, with the comparison of proportion, these two groups has a small impact towards the whole analysis. Otherwise, positive and negative sentiment stay constant throughout all groups in a range of 0.2359 . So, the level of sentiment does not change much with the change of locations. From the observation of neutral sentiment plot, there are no specific pattern being detected and it is not constant from all group.

To begin the comparison, three groups are selected with highest frequency words appeared compared to all groups. Group 1 with 2720 words, Group 9 with 1250 words and Group 10 with 1002 words are selected. Due to the others group have words frequency lower than 1000 , the impact towards the analysis is significantly lower than the three selected group.

The most appear words of WMatrix category for Group 1 is General \& Abstract terms such as wrong, proof, and victim. Example of the tweet saying "\#LondonBridgeAttack is a shame on humanity. What's wrong with us?". From this category is mainly discuss about evaluation of accuracy ,true/false and the damage towards victims. There are negative emotion words such as abuse, attack and stabbed to express emotional of violent and angry towards the topic. The following group that were discussed are social actions, states and processes containing words such as muslim, treating, leading, solidarity, racist and strong. Example "One of our Muslim nurses was racially abused on her way home, after treating \#LondonBridgeAttack victims". These tweets contain two categories of religion and negative emotion of violated.

From the results of Group 9, negative emotion words continue appeared, for example, threat, worry and attack, to express their emotions towards this incident. Users from Group 9 also discuss a topic related to government and public domain. Words like terrorist, terrorism, police, 
citizen, armed and unarmed are being used several times in the tweets to discuss the topic. For example, "Incredibly brave but incredibly tragic. If he was armed, he would have been able to eliminate the threat immediately. \#LondonBridgeAttack". Social action, states and processes are also discussed in this group; words like preventing, fight and protect containing the meaning of helping or hindering others appeared more frequently than others.

Example of a tweet, "Dear London, if u plan to fight terrorism \&amp; protect your citizens LEOs must be armed! 2b unarmed is a suicide mission! \#LondonBridgeAttack". They have discussed public domain, and social action of what should be done after the incident happened.

Group 10 has the similarity of group 9 and 1 discussion that related to emotional with words like terror, cruel, threat, attack and peace. General \& Abstract terms such as wrong, proof, victim and safe, and lastly government and public domain category

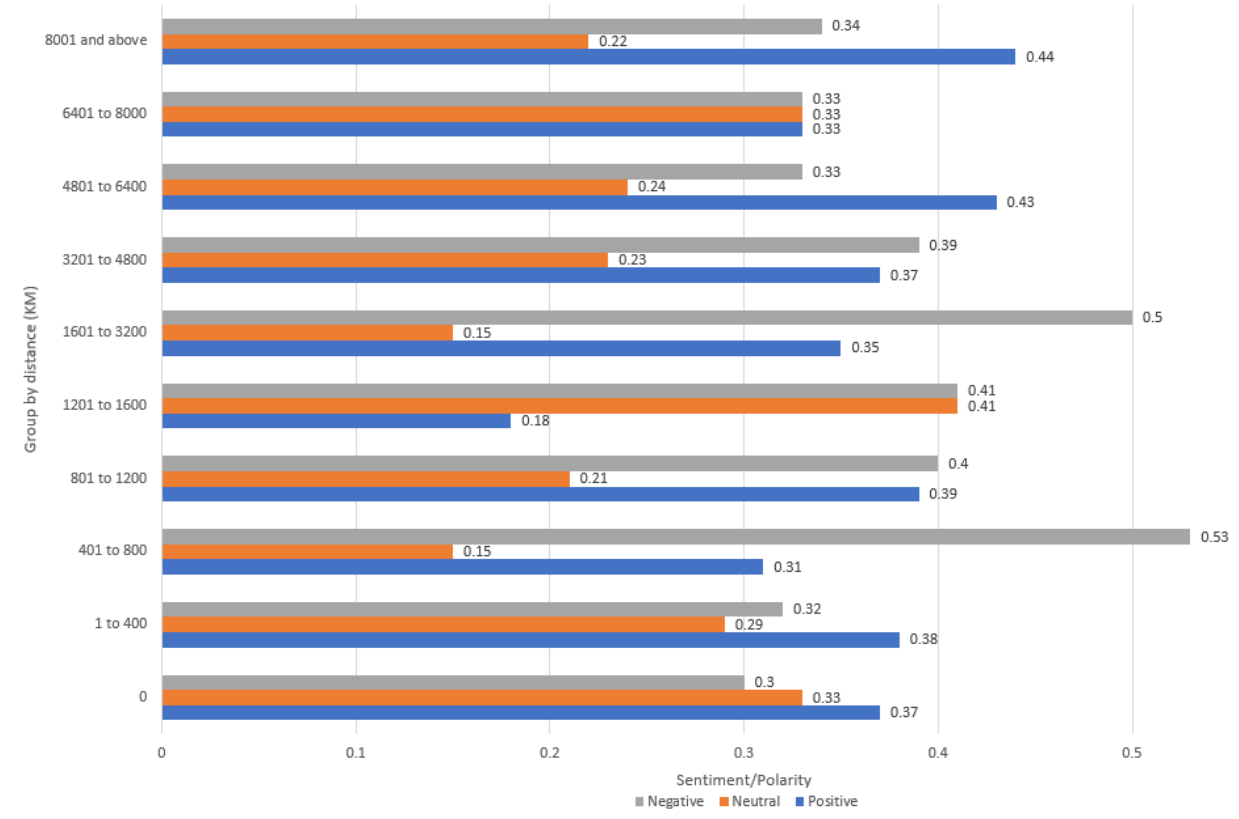

Figure1: Sentiment polarity vs. distance from London

with words of perpetrators, police and terrorist appeared. Example, "How about" One Love London" as we have twice been victims of terror? \#mayoroflondon \#OneLoveMachester\#arianagrande\#LondonBridgeAttack. General terms such as victims constantly appear due it's a terrorism event; therefore, emotional words like terror and threat will always come accordingly to express their feeling about it.

TABLE V. CATEGORIES OF TOPIC DISCUSSED

\begin{tabular}{|l|l|l|l|}
\hline Group & $\mathbf{1}$ & $\mathbf{9}$ & $\mathbf{1 0}$ \\
\hline $\begin{array}{l}\text { Topic } \\
1\end{array}$ & $\begin{array}{l}\text { Emotional } \\
\text { Actions, States } \\
\text { \& Processes }\end{array}$ & $\begin{array}{l}\text { Emotional } \\
\text { Actions, States \& } \\
\text { Processes }\end{array}$ & $\begin{array}{l}\text { Emotional } \\
\text { Actions, States } \\
\text { \& Processes }\end{array}$ \\
\hline $\begin{array}{l}\text { Topic } \\
2\end{array}$ & $\begin{array}{l}\text { General \& } \\
\text { Abstract terms }\end{array}$ & $\begin{array}{l}\text { Govt. \& the } \\
\text { public domain }\end{array}$ & $\begin{array}{l}\text { General \& } \\
\text { abstract terms }\end{array}$ \\
\hline $\begin{array}{l}\text { Topic } \\
3\end{array}$ & $\begin{array}{l}\text { Social actions, } \\
\text { states \& } \\
\text { Processes }\end{array}$ & $\begin{array}{l}\text { Social actions, } \\
\text { states \& } \\
\text { Processes }\end{array}$ & $\begin{array}{l}\text { Govt. \& the } \\
\text { public domain }\end{array}$ \\
\hline
\end{tabular}

Table $\mathrm{V}$ is created associated with the number of grouping and category or topic being discussed. There are similarities and differences between each group. Users from the different geographical area do have different opinions, but the primary topic of discussion are close to each other.

To discover the relationship between sentiment and credibility, we have used the data from Table III to perform correlation analysis using SAS Enterprise to determine whether these two variables are correlated to each other. Using Pearson correlation coefficients, the results showing the relationship between sentiment and credibility are weak. From correlation score, -0.35255 , $0.10587,0.2188$ (Table VI) for positive, neutral and negative, all of the scores are closer to 0 compared to 1 and -1 . There is no pattern found in the plots. Therefore, we can conclude that relationship with sentiment and credibility are extremely weak, so, sentiment will not cause much effect to the level of credibility of public opinion.

\section{The Credibility of Public opinion}

TABLE VI. CORRELATION COEFFICIENT

\begin{tabular}{|l|l|}
\hline Pearson Correlation Coefficients, $\mathbf{N}=\mathbf{1 0}$ \\
\hline & Credibility \\
\hline Positive & -0.35255 \\
\cline { 2 - 2 } & 0.3177 \\
\hline \multirow{2}{*}{ Neutral } & 0.10587 \\
\cline { 2 - 2 } & 0.7710 \\
\hline Negative & $0 . .21880$ \\
\hline
\end{tabular}




\subsection{6}

\section{CONCLUSION}

This paper has described our methods to measure the level of credibility from users towards a topic and find out any factors that might affect public opinion and the level of credibility of it. Sentiment analysis were carried out using tools and further interpret with geographical location to observe the changes of it. We have discovered that people from different locations will have different opinions towards a similar topic, although the discussion has several similarities and differences in categories when users are discussing the same category, their in-depth discussion is similar as well. From our performed analysis, we eliminated the relationship between the level of credibility and sentiment are correlated to each other. The distance of tweet generated compared to an incident occur is a factor that required to be further analysed as the result shown different opinions being discussed from different geographical locations.

Capitalising community opinions with methods about a topic issue has benefit that it provides useful information that can be used to determine the credibility of a piece of information. We suggest that demographic data of Twitter users need to be included to measure the level of credibility by observing the public reputation of each user as well. By using the representative tweets in a cluster, it provides an explanation of why agree or disagree towards the topic [9].

The information provided about the degree to which a tweet is credible is not enough to convince users. The explanation of the algorithms and methods used in this paper helps users to understand the reason of evaluation and system's credibility assessment although certain users do not agree with it. The main drawback of this study are the dataset purchased does not provide information that is relevant enough to perform further analysis by having layers of tweets with retweets associated with primary tweet that claimed for a topic. Therefore, the ability to identify highly reputable and authoritative tweet associate with retweets of it for a particular topic will save a significant amount of effort and time and improve the model prediction accuracy and precision.

\section{ACKNOWLEDGMENT}

This research was funded by University of Macau (File no. MYRG2019-00136-FST).

\section{REFERENCES}

[1] K. Kim, Y. M. Baek, and N. Kim, "Online news diffusion dynamics and public opinion formation: A case study of the controversy over judges' personal opinion expression on SNS in Korea," Soc. Sci. J., vol. 52, no. 2, pp. 205-216, 2015, doi: 10.1016/j.soscij.2015.02.001

[2] P. E. Converse, "Changing Conceptions of Public Opinion in the Political Process," Public Opin. Q., vol. 51, no. 4, pp. S12-S24, 1987, doi: 10.1093/poq/51.4_PART_2.S12.

[3] V. Price and M.-L. Hsu, "Public Opinion About AIDs Policies: Attitudes Toward Homosexuals," Public Opin. Q., vol. 56, pp. 29 52, 1992.

[4] J. Arregui and M. J. Creighton, "Public Opinion and the Shaping of Immigration Policy in the European Council of Ministers," J. Common Mark. Stud., vol. 56, no. 6, pp. 1323-1344, 2018, doi: $10.1111 /$ jcms. 12745
[5] J. Lyons, "Moral dialogs and public opinion research," Soc. Sci. J. vol. 55, no. 1, pp. 31-33, 2018, doi: 10.1016/j.soscij.2018.02.009.

[6] B. E. Lauderdale, C. Hanretty, and N. Vivyan, "Decomposing public opinion variation into ideology, idiosyncrasy, and instability," J. Polit., vol. 80, no. 2, pp. 707-712, 2018, doi: 10.1086/695673.

[7] R. Kardooni, S. B. Yusoff, F. B. Kari, and L. Moeenizadeh, "Public opinion on renewable energy technologies and climate change in Peninsular Malaysia," Renew. Energy, vol. 116, pp. 659-668, 2018, doi: 10.1016/j.renene.2017.09.073

[8] D. Chong and J. N. Druckman, "A theory of framing and opinion formation in competitive elite environments," J. Commun., vol. 57, no. 1, pp. 99-118, 2007, doi: 10.1111/j.1460-2466.2006.00331.x.

[9] A. Gamson, William a., Modigliani, "Media Discourse and Public Opinion on Nuclear Power: A Constructionist Approach Author ( $\mathrm{s}$ ): William A. Gamson and Andre Modigliani Source: The American Journal of Sociology , Vol . 95 , No . 1 ( Jul ., 1989 ), pp . 1-37 Published by: The University," Am. J. Sociol., vol. 95, no. 1, pp. 1-37, 2009.

[10] M. Clemente and T. J. Roulet, "Public opinion as a source of deinstitutionalization: A 'spiral of silence' approach," Acad. Manag. Rev., vol. 40, no. 1, pp. 96-114, 2015, doi: 10.5465/amr.2013.0279

[11] W. L. Bennett and S. Iyengar, "A new era of minimal effects? The changing foundations of political communication," J. Commun., vol. 58, no. 4, pp. 707-731, 2008, doi: 10.1111/j.14602466.2008.00410.x.

[12] R. L. Holbert, R. K. Garrett, and L. S. Gleason, "A new era of minimal effects? A response to Bennett and Iyengar," J. Commun., vol. 60 , no. 1 , pp. $15-34,2010$, doi: 10.1111/j.14602466.2009.01470.x.

[13] D. Chong and J. N. Druckman, "Framing Theory," Annu. Rev. Polit. Sci., vol. 10, no. 1, pp. 103-126, 2007, doi: 10.1146/annurev.polisci.10.072805.103054.

[14] D. A. Scheufele; and D. Tewksbury, "Framing, Agenda Setting, and Priming: The Evolution of Three Media Effects Models," J Commun., vol. 56, no. 4, pp. 864-866, 2006, doi: 10.1111/j.14602466.2006.00326.x.

[15] S. Kiousis, "Mass Communication and Society Public Trust or Mistrust? Perceptions of Media Credibility in the Information Age," Mass Commun. Soc., vol. 4, no. 4, pp. 381-403, 2001, doi 10.1207/S15327825MCS0404

[16] B. J. B. Singer, "Metro Wide Web : Changes Role Online," 2001.

[17] C. T. Christen and K. E. Huberty, "Media Influence? the Effects of Local, on Public Opinion Inferences," Journal. Mass Commun. Q., vol. 84, no. 2, pp. 315-334, 2007.

[18] A. K. Kausar and A. A. Leema, "Real-Time Event Detection and Earthquake Reporting System for the Twitter Users," Int. J. Bus. Anal. Intell., vol. 2, no. 1, pp. 41-45, 2014.

[19] S. Vieweg, A. L. Hughes, K. Starbird, and L. Palen, "Microblogging during two natural hazards events: What twitter may contribute to situational awareness," Conf. Hum. Factors Comput. Syst. - Proc., vol. 2, no. January, pp. 1079-1088, 2010, doi: $10.1145 / 1753326.1753486$.

[20] A. Lee Hughes and L. Palen, "Twitter adoption and use in mass convergence and emergency events," Int. J. Emerg. Manag., vol. 6, no. 3-4, pp. 248-260, 2009, doi: 10.1504/IJEM.2009.031564.

[21] K. Starbird, L. Palen, A. L. Hughes, and S. Vieweg, "Chatter on The Red: What hazards threat reveals about the social life of microblogged information," Proc. ACM Conf. Comput. Support. Coop. Work. CSCW, pp. 241-250, 2010, doi 10.1145/1718918.1718965.

[22] P. L. Teh, L. P. Huah, and Y. W. Si, "The intention to share and reshared among the young adults towards a posting at social networking sites," in Advances in Intelligent Systems and Computing, 2014, vol. 275 AISC, no. VOLUME 1, pp. 13-21, doi: 10.1007/978-3-319-05951-8_2.

[23] B. Hilligoss and S. Y. Rieh, "Developing a unifying framework of credibility assessment: Construct, heuristics, and interaction in context," Inf. Process. Manag., vol. 44, no. 4, pp. 1467-1484, 2008, doi: 10.1016/j.ipm.2007.10.001 
[24] D. H. Widyantoro and Y. Wibisono, "Modeling credibility assessment and explanation for tweets based on sentiment analysis," J. Theor. Appl. Inf. Technol., vol. 70, no. 3, pp. 540$548,2014$.

[25] P. Barberá, "Birds of the same feather tweet together: Bayesian ideal point estimation using twitter data," Polit. Anal., vol. 23, no. 1, pp. 76-91, 2015, doi: 10.1093/pan/mpu011.

[26] T. Zeitzoff, J. Kelly, and G. Lotan, "Using social media to measure foreign policy dynamics: An empirical analysis of the IranianIsraeli confrontation (2012-13)," J. Peace Res., vol. 52, no. 3, pp. 368-383, 2015, doi: 10.1177/0022343314558700.

[27] C. Ai, B. Chen, L. He, K. Lai, and X. Qiu, "The national geographic characteristics of online public opinion propagation in
China based on WeChat network," Geoinformatica, vol. 22, no. 2 pp. 311-334, 2018, doi: 10.1007/s10707-017-0311-4

[28] L. Fowler, "Tracking state trends in environmental public opinion," Soc. Sci. J., vol. 54, no. 3, pp. 287-294, 2017, doi: 10.1016/j.soscij.2017.02.003.

[29] M. Schmierbach and A. Oeldorf-Hirsch, "A Little Bird Told Me, So I Didn't Believe It: Twitter, Credibility, and Issue Perceptions," Commun. Q., vol. 60, no. 3, pp. 317-337, 2012, doi: 10.1080/01463373.2012.688723.

[30] I. Pak, P. L. Teh, and Y. N. Cheah, "Hidden sentiment behind letter repetition in online reviews," J. Telecommun. Electron. Comput Eng., vol. 10, no. 3-2, pp. 115-120, 2018. 
